\title{
Interview with Amit Basu on "The Information Systems Society of the INFORMS"
}

\author{
Professor Amit Basu is the Carr P Collins Chair in MIS and president of the INFORMS \\ Information Systems Society (ISS). His areas of expertise include virtual organizations, \\ knowledge management, technology and innovation management, information \\ management, strategic information systems, IS in health care, management information \\ systems, e-commerce, database design and implementation, and computer-based \\ information systems. Amit is Associate editor of Management Science, Information \\ Technology \& Management, and the POMS journal.
}

DOI 10.1007/s12599-013-0280-6

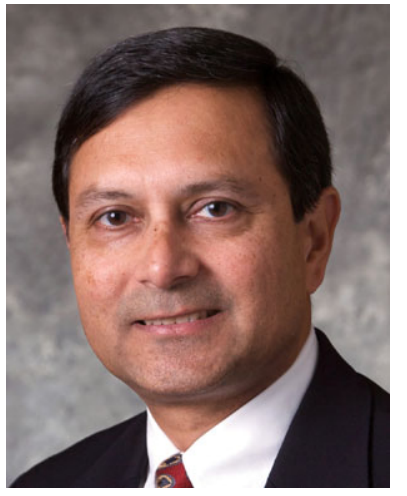

Prof. Amit Basu

Carr P Collins Chair in Management Information Systems

SMU - Cox School of Business

6212 Bishop Blvd.

Dallas, TX 75275-0333

USA

\section{Interview by}

Prof. Dr. Martin Bichler ( $\varangle)$

Decision Sciences \& Systems

Department of Informatics

TU München

Boltzmannstr. 3

85748 Garching

Germany

bichler@in.tum.de

Published online: 2013-07-05
This article is also available in German in print and via http://www. wirtschaftsinformatik.de: Bichler $M$ (2013) Interview mit Amit Basu zum Thema "Wirtschaftsinformatik in der INFORMS". WIRTSCHAFTSINFORMATIK. doi: 10.1007/s11576-0130375-1.

(C) Springer Fachmedien Wiesbaden 2013

BISE: The INFORMS is seen as a much respected organization covering all areas of the management sciences. How do you see the role of ISS within the INFORMS and how did it develop over the years?

Basu: The field of information systems is quite diverse, drawing upon a variety of reference disciplines ranging from Computer Science and Operations Research to Economics and Psychology. Within this broad scope, it is clear that Management Science and Operations Research play a very significant role in our field, including core training of graduate students and research methodology. The ISS provides a valuable forum for academic and industrial researchers in information systems, particularly those who use Management Science and Operations Research methods and tools in their work. This makes the society very inclusive, so Statisticians, Econometricians, algorithm developers, IS designers, modelers and empiricists who work on information systems and issues related to their design and use, can all find value in the society's activities.

BISE: Where do you see the specific role of the INFORMS ISS with respect to the Association for Information Systems (AIS), but also relative to IS communities in the Academy of Management, the $\mathrm{ACM}$, and the IEEE Computer Society?

Basu: As I indicated earlier, the scope of information systems research spans all those communities. The AIS is a broad-spectrum organization intended to span the whole field, so in principle, the scope of ISS is included within AIS. The other organizations you cited were created by communities within different reference disciplines, such as organization theory/management, computer science and computer/software engineering. These are key resources for information systems researchers as well. In my view, their fields of interest overlap significantly with those of ISS, and their activities nicely complement those of ISS. I can also see some interesting synergies that can be realized through collaborative efforts, such as joint sponsorship of some activities.

BISE: Information technology is still developing rapidly. The importance of these technological changes for research varies across different research questions. But, how important is it to have information technology and engineering classes as part of IS curricula? This has an impact on the types of jobs IS students will apply for.

Basu: I think you have to look at two types of curricula. For undergraduate programs and programs intended to train students for industry jobs, you need curricula that develop high-demand skills in programming, business analysis, software engineering, systems analysis, systems development, project management, IT consulting, etc. They also 
should develop familiarity with the information technology used by most companies, such as database systems, application and system development tools, enterprise systems, networks, mobile devices and systems, etc., and the issues and processes underlying their design and management.

At the graduate level or for programs geared towards training researchers, the focus needs to be on teaching about research tools and core IT, followed by exposure to open research problems and the state of the art. At this level, I see schools differing more significantly, based on the research expertise they have on their faculty.

This distinction is important because it impacts the basis on which schools can distinguish themselves, and focus their development and innovation efforts.

BISE: Given the interdisciplinary nature of research in IS, there is also a broad set of research methods that is nowadays being used ranging from analytical modeling to algorithm design, lab experiments and field studies. Other disciplines such as Marketing or Operations Management are based on a core set of models and methods, which largely shape their curricula. This is different in IS and the methods are largely based on the phenomena being analyzed, may it be social networks, online auctions, or technology adoption. This can be seen as a virtue and a vice. On the one hand, this has helped picking up new and relevant topics. On the other hand, there are regular discussions on the identity of the field. What do you consider core elements of an IS curriculum? Which role plays the ISS in this regard?

Basu: I believe my previous answer gets at your first question here. The notion of "core curriculum" depends upon the level and orientation of the program. With respect to the role of ISS, I think by bringing together a broad range of IS researchers working across the spectrum of problems, methods and tools, the society's activities can complement the curricula and programs of each individual school, and enable researchers to build a broader awareness of the field in which they work and study.

BISE: ISR is the flagship journal of the INFORMS ISS. Publications in a few journals such as ISR, Management Science, and MISQ have become very important for getting tenure in many US universities. How do you perceive the developments in the IS job market and the role of different types of journals?

Basu: The breadth and diversity of the IS field makes it particularly difficult to focus on a small set of journals. The ones you mentioned are all well-respected, and commonly cited as being the best in the field. At the same time, depending on the specific problem being addressed, there are a number of high quality journals, including many transactions of the ACM and IEEE that are equally well-respected. My view is that researchers should publish their work where it will be most widely appreciated and have the greatest impact (e.g., through citations). Since most people do a variety of work, over time this approach should lead to publications in both broad-spectrum and specialized journals.

The question of what matters most for performance evaluation also needs to factor in the context, i.e., the type of school. Business schools tend to lean towards journals published by societies such as INFORMS because these societies are well-known in other business disciplines as well. On the other hand, information schools (the so-called i-schools) and IS departments within engineering schools are familiar with ACM and IEEE publications as well - if not more. These preferences tend to get reinforced implicitly through the schools' hiring and development processes.

Finally, it is important to note that IS is a relatively young field, and one of the most dynamic. So new ideas, areas of focus and opportunities are still emerging, and will very likely lead to the emergence of yet more journals.

BISE: How does the ISS support research in IS? Beyond the support for ISR, which meetings and conferences are currently supported by the ISS and how do you see the role of these individual meetings?

Basu: Currently, we support ISR directly, by enhancing its publication capacity. We are also initiating some "best paper" awards for IS papers in several journals. Beyond that, we sponsor/support several academic research conferences and workshops, including
CIST, SCECR, and some IS teaching workshops. Ultimately, the forums we support are a function of our members' interests, and we are always open to new ideas on this front.

BISE: IS is a relatively young field. How do you see the development of the IS discipline over time? Which trends and topics do you see emerge? What do you see as the biggest challenge for the IS community?

Basu: I think we are in a very exciting period for the IS field. Modern organizations are increasingly automated and data-driven, and modern society is increasingly networked. The age of sensors and sensor-based systems is just dawning. So over the next few years, I think we will see tremendous innovation in managing, analyzing and leveraging data, both within companies and between companies, people and things (devices, appliances, etc.).

The biggest challenge for the academic field of IS is to keep up with these huge and rapid changes, and to stay relevant. Already, we see academic research lagging technological innovation and even IT use and practice. I wonder about the effectiveness of a research model that implies a gestation period of several years, in a context where the technology and issues being researched change over even a few months.

BISE: You have worked on a number of different research areas in your career. Much of your research is devoted to electronic markets. Where do you see some of the future IS research challenges in these areas?

Basu: Electronic markets and the emergence of a global networked business and communication infrastructure have dramatically changed whole industries and even society in general. In recent years, four key trends have emerged - mobility, sensor-systems, cloud computing and big data. I think these will provide fodder for a large variety of IS research questions, not only separately but also in their interactions. With these opportunities, as well as the plethora of existing issues that IS researchers are already studying, I see no threat of stagnation in the field for the foreseeable future.

BISE: Professor Basu, we thank you very much for this interview. 